\title{
Pengaruh Konsentrasi Saccharomyces cereviceae Terhadap Produksi Bioetanol Berbahan Dasar Batang Jagung
}

\author{
Muhammad Rijal ${ }^{1}$, Adila Rumbaru ${ }^{2}$, Abajaidun Mahulauw ${ }^{3}$ \\ ${ }^{1,3}$ Dosen Program Studi Pendidikan Biologi, Fakultas Ilmu Tarbiyah dan Keguruan \\ Institut Agama Islam Negeri Ambon \\ ${ }^{2}$ Mahasiswa Program Studi Pendidikan Biologi, Fakultas Ilmu Tarbiyah dan Keguruan \\ Institut Agama Islam Negeri Ambon \\ ${ }^{1}$ Email: rijal_rijal82@yahoo.co.id
}

\begin{abstract}
Abstrak: Jenis penelitian ini adalah kuantitatif eksperimen laboratorium. Penelitian ini dilaksanakan selama 2 minggu dimulai tanggal 13-25 September 2018, bertempat di Laboratorium MIPA IAIN Ambon. Objek penelitian ini adalah limbah batang jagung yang terdapat di Desa Waiheru, Kota Ambon Provinsi Maluku. Hasil penelitian menunjukan ada perlakuan konsentrasi ragi 1\% menghasilkan kadar bioetanol terendah yaitu sebesar $0,26 \%$. Sedangkan, konsentrasi ragi 4\% dengan waktu fermentasi 6 hari menghasilkan kadar bioetanol tertinggi yaitu sebesar 1,25\%. Pada perlakuan konsentrasi ragi $1 \%$ menghasilkan volume terendah bioetanol yaitu sebesar 92,666 ml. Sedangkan, pada perlakuan konsentrasi ragi $4 \%$ menghasilkan volume tertinggi bioetanol sebesar $97,333 \mathrm{ml}$.
\end{abstract}

\section{Kata Kunci: Saccharomyces ceriveceae, Produksi Bioetanol, Batang Jagung}

Abstract: This type of research is quantitative laboratory experiments. This research was conducted for 2 weeks starting from 13-25 September 2018, at the IAIN MIPA Laboratory in Ambon. The object of this research is corn stem waste found in Waiheru Village, Ambon City, Maluku Province. The results showed that there was a treatment of $1 \%$ yeast concentration producing the lowest bioethanol level of $0.26 \%$. Whereas, $4 \%$ yeast concentration with 6 days fermentation time produced the highest bioethanol level which was equal to $1.25 \%$. In the treatment of $1 \%$ yeast concentration produced the lowest volume of bioethanol which was equal to $92.666 \mathrm{ml}$. Meanwhile, the treatment of $4 \%$ yeast concentration produced the highest volume of bioethanol of 97,333 ml.

Key Words: Saccharomyces ceriveceae, Bioethanol Production, Corn Stalks

Jagung adalah salah satu tanaman produk pertanian yang banyak dihasilkan di Indonesia. Pada tahun 2007 produksi jagung mencapai 13,287.527 ton dan diiperkirakan meningkat menjadi 14.854.050 ton pada tahun 2008 jumlah tanaman jagung meninggkat sekitar 30 $\%$ sehingga batang jagung yang menjadi limbah dari buah jagung sekitar $30 \%$ jika dikonversikan dengan jumlah produksi jagung pada tahun 2008 maka negara Indonesia

BIOLOGI SEL (YOL 8 NO 1 EDISI JAN-JUN 2019 ISSN 2252-858X/E-ISSN 2541-1225) PAGE 59 
berpotnsi menghasilkan batang jagung sebesar 4.456 .215 ton. Jumlah tersebut dapat dikatakan sangat banyak dan akan menjadi sangat potensial jika dimanfaatkan secara tepat (Fachry, 2013).

Pemanfaatan limbah batang jagung masih belum optimal dalam pemanfaatannya ditambah lagi dengan produksi sampah yang begitu besar setiap harinya semakin memberikan dampak buruk juga bagi lingkungan. Menurut Pramono dari total sampah organik, sekitar 60\% merupakan sayur-sayuran dan 40\% merupakan daun-daunan, kulit buah-buahan dan sisa makanan (Lestari,2015). Tumbuhan yang potensial untuk menghasilkan bioetanol antara lain tanaman yang memiliki kadar karbohidrat tinggi seperti tebu, nira, ubi kayu, pisang, ubi jalar serta tanaman jagung yang merupakan salah satu tanaman yang dapat dimanfaatkan sebagai sumber produksi bioetanol sebab sejauh ini biomassa jagung mengandung lignoselulosa sangat dimungkinkan untuk dimanfaatkan menjadi bioethanol (Fitriani, 2013).

Bioetanol merupakan cairan hasil fermentasi gula dari sumber karbohidrat (pati) dengan menggunakan bantuan mikroorganisme. Produksi bioetanol dari tanaman yang mengandung pati atau karbohidrat dapat dilakukan melalui proses konversi karbohidrat menjadi gula (glukosa) dengan metode hidrolisis dan fermentasi. Kelebihan bioetanol bila dibandingkan dengan bahan bakar memiliki oksigen yang lebih tinggi (35\%) dan BBM $(16,66 \%)$ sehingga dapat terbakar dengan sempurna, angka oktannya tingginya (118) dan BBM (88) serta mengandung emisi gas CO sekitar 0,89\% dan BBM 2,5\% sehingga lebih ramah lingkungan. Saat ini, banyak bahan baku sebagai alternative dari sektor pangan yang mengandung selulosa memiliki potensi untuk dapat menghasilkan bioetanol. Salah satunya adalah tanaman jagung.

Jagung merupakan salah satu tanaman yang dapat dimanfaatkan sebagai sumber penghasil bioetanol. Jagung pada biasanya oleh masyarakat ketika musim panen meninggalkan limbah berupa batang jagung yang tidak lagi dimanfaatkan. Hal ini, bilamana akan terus terjadi dapat menyebabkan pencemaran limbah di alam. Perlu diketahui bahwa jagung selain sebagai kebutuhan pokok yang dapat dikonsumsi oleh masyarakat karena kandungan karbohidratnya, selain buahnya sebagai bahan makanan batangnyapun juga dapat dimanfaatkan. Kandungan selulosa yang terdapat pada jagung (45\%), hemiselulosa (35\%) dan lignin (15\%). Masing-masing kandungan ini merupakan senyawa-senyawa yang potensial untuk dapat dikonversi menjadi senyawa lain secara biologi, selulosa merupakan sumber karbon yang dapat digunakan mikroorganisme sebagai substrat dalam proses fermentasi untuk menghasilkan produk seperti bioethanol (Rasyid, 2013). Oleh karena itu, produksi bioetanol perlu dikembangkan untuk mengurangi jumlah limbah batang jagung dan dapat digunakan sebagai pengganti bahan bakar yang diproduksi menjadi bioetanol dengan bantuan fermentasi oleh Saccharomyces cereviceae. 
Saccharomyces cereviceae merupakan bakteri yang termasuk dalam family Saccharomycetales dengan genus Saccharomyces bentuknya sel khamir bundar, memanjang seperti benang dan menghasilkan psedomiselium. Khamir ini hidup pada kondisi $\mathrm{pH}$ 3-6 dengan temperature maksimal $40-50^{\circ} \mathrm{C}$ dan minimal $0^{\circ} \mathrm{C}$ (Moeksin, 2012). Saccharomyces cerevicae lebih banyak digunakan untuk memproduksi bioetanol secara komersial bila dibandingkan dengan bakteri atau jamur. Hal ini disebabkan karena Saccharomyces cereviceae dapat memproduksi alcohol dalam jumlah besar dan mempunyai toleransi pada kadar alcohol yang tinggi. Kadar alcohol yang dihasilkan sebesar $8-20 \%$ pada kondisi optimum. Secara umum mikroorganisme dapat tumbuh dan memfermentasi gula menjadi etanol secara efisien pada $\mathrm{pH} 3,5-6,0$ dan suhu $28-35^{\circ} \mathrm{C}$

Selain itu, juga harus dilihat proses delignifikasi yang dilakukan pada ubi kayu diperoleh pada konsentrasi $\mathrm{NaOH}$ terbaik adalah $25 \%$ pada suhu $128^{\circ} \mathrm{C}$ dengan waktu lama delignifikasi selama 60 menit. Hasil penelitian Ikbal tahun 2010 bahwa hasil proses delignifikasi pada jerami padi terjadi pada kondisi operasi terbaik konsentrasi $\mathrm{NaOH} 10 \%$ dan suhu $100^{\circ} \mathrm{C}$ dengan waktu delignifikasi selama 24 jam (Fitriani, 2013). Berdasarkan uraian diatas maka perlu dikaji lebih dalam lagi pengaruh delignifikas pada limbah batang jagung untuk produksi bioetanol.

\section{METODE PENELITIAN}

Jenis penelitian ini adalah penelitian kuantitatif eksperimen laboratorium dengan tujuan untuk menganalisis dan mengetahui pengaruh pemberian variasi konsentrasi kadar Saccharomyces cereviceae terhadap produksi bioetanol berbahan dasar limbah batang jagung. Variabel dalam penelitian ini terdiri atas dua variabel, yaitu variabel terikat dan variabel bebas. Adapun yang menjadi variabel terikatnya adalah produksi bioetanol berbahan dasar limbah batang jagung Sedangkan, variabel bebasnya adalah variasi konsentrasi Saccharomyces cereviceae.

Percobaan produksi bioetanol berbahan dasar limbah batang jagung dengan dan fermentasi oleh Saccharomyces cereviceae, menggunakan Rancangan Acak Lengkap (RAL) dengan kombinasi konsentrasi banyaknya ragi. Percobaan dilakukan dengan 4 perlakuan 3 kali pengulangan sehingga diperoleh 12 unit perlakuan selama 6 hari. Kombinasi perlakuan tersebut adalah sebagai berikut:

1. $\mathrm{K}_{1}=$ Konsentrasi ragi $1 \mathrm{~g} / 10 \mathrm{~g}$ bahan

2. $\mathrm{K}_{2}=$ Konsentrasi ragi $2 \mathrm{~g} / 10 \mathrm{~g}$ bahan

3. $\mathrm{K}_{3}=$ Konsentrasi ragi $3 \mathrm{~g} / 10 \mathrm{~g}$ bahan

4. $\mathrm{K}_{4}=$ Konsentrasi ragi $4 \mathrm{~g} / 10 \mathrm{~g}$ bahan.

\section{Prosedur Penelitian}

1. Tahap Persiapan Bahan Baku

a. Batang jagung disortir untuk dapat menentukan batang jagung yang bagus. Dalam artian batang jagung yang masih segar.

BIOLOGI SEL (YOL 8 NO 1 EDISI JAN-JUN 2019 ISSN 2252-858X/E-ISSN 2541-1225) PAGE 61 
b. Batang jagung dicuci dengan air bersih hingga tidak ada kotoran yang masih menempel.

c. Batang jagung dipotong kecil-kecil dengan pisau

d. Batang jagung kemudian dijemur \pm 7 hari sampai benar-benar kering

e. Batang jagung yang telah kering kemudian dihaluskan dengan menggunakan parutan, lumpang dan alu.

f. Kemudian di blender hingga diperoleh tepung bubuk batang jagung yang lebih halus.

g. Batang jagung yang sudah halus kemudian di tapis dengan menggunakan ayakan setelah itu tepung batang jagung dimasukan kedalam plastik gula.

\section{Tahap Pelaksanaan}

a. Pengenceran Bahan

1. $\mathrm{HCl}$ pekat sebanyak $945 \mathrm{ml}$ di campurkan dengan aquades sebanyak $3555 \mathrm{ml}$ (setara dengan 3 liter setengah) untuk membuat $\mathrm{HCl} 21 \%$.

2. $\mathrm{NaOH}$ ditimbang sebanyak $400 \mathrm{~g}$ di masukan ke dalam toples yang berisi air sebanyak $2000 \mathrm{ml}$ (setara dengan 2 liter) untuk membuat $\mathrm{NaOH} 20 \%$.

b. Hidrolisis

1. Bubuk batang jagung di timbang beratnya yaitu $10 \mathrm{~g}$ per sampel lalu di masukan kedalam beker gelas.

2. Masukan $\mathrm{HCl} 21 \%$ kedalam beker gelas yang berisi bubuk batang jagung sebanyak $200 \mathrm{ml}$ per sampel.

3. Dimasukan ke dalam oven dengan suhu $50^{\circ} \mathrm{C}$ selama 2 jam. Setelah itu di keluarkan dari oven dan di dinginkan lalu di saring dan diperas.

4. Kemudian itu tuangkan ke botol selai dan di campurkan dengan $\mathrm{NaOH} 20 \%$ untuk di ukur asam $\mathrm{pH}$ basah dengan menggunakan kertas unifersal indicator dengan $\mathrm{pH} 5$.

5. Setelah mendapatkan nilai $\mathrm{pH}$ diamkan selama 24 jam untuk proses fermentasi.

b. Fermentasi

1. Masukan aquades ke dalam labu erlemeyer sebanyak $105 \mathrm{ml}$.

2. Gula ditimbang sebanyak $10 \mathrm{~g}$. setelah itu masukan gula kedalam labu erlemeyer untuk di larutkan hingga menghasilkan larutan gula.

3. Larutan gula dipanaskan di hot plate selama 10 menit kemudian larutan gula tersebut di dingginkan.

4. Setelah itu menimbang ragi dengan berat $1 \mathrm{~g}, 2 \mathrm{~g}, 3 \mathrm{~g}, 4 \mathrm{~g}$, untuk masig-masing perlakuan

5. Kemudian masukan ragi kedalam labu erlemeyer yang berisi larutan gula setelah itu diaduk hingga larut

6. Larutan gula dan ragi yang sudah larut sebanyak $30 \mathrm{ml}$ dimasukan kedalam sampel untuk proses fermentasi selama 144 jam (6 hari) dan ditutup dengan alumanium voil

c. Destilasi 
1. Rangkaikan alat destilasi yang terdiri dari labu destilasi, alat pendingin, pompa air, ember, wadah pemanas, magnetik stirrer, 2 buah batang statif.

2. Cok pompa air hingga air masuk ke dalam alat pendingin.

3. Masukan sampel yang sudah di fermentasi kedalam labu dstilasi.

4. Masukan minyak kelapa ke dalam wadah alumanium untuk di panaskan.

5. Letakan labu destiasi di dalam wadah yang berisi minyak.

6. Pasangkan pegangan labu destilasi pada penjepit batang statif.

7. Pastikan alat pendingin rapat dengan saluran penguapan labu dstilasi kemudian dipanaskan dengan suhu $78^{\circ} \mathrm{C}$.

8. Tunggu hingga menguap dan letak kan botol selai pada corong alat pendinggin.

9. Biarkan hingga tetes demi tetes mengalir sampai sleesai proses destilasi.

10. Dimasukan ke dalam piknometer dngan menggunakan pipet tetes dan di timbang di neraca digital untuk menggukur kadar bioethanol

\section{HASIL DAN PEMBAHASAN}

Tanaman jagung merupakan salah satu tanaman yang dapat dimanfaatkan sebagai sumber bioetanol. Biomassa batang jagung merupakan sampah yang sejauh ini masih belum banyak dimanfaatkan menjadi produk yang memiliki nilai tambah. Batang jagung yang termasuk biomassa mengandung lignoselulosa sangat dimungkinkan untuk dimanfaatkan menjadi bioetanol karena memiliki kandungan selulosa yang cukup banyak.

Komponen lignoselulosa merupakan sumber utama untuk menghasilkan produk bernilai seperti gula dari hasil fermentasi. Berbagai produk nilai tambah dari limbah lignoselulosa diantaranya adalah bioetanol. Bioetanol dapat dihasilkan dari bahan yang mengandung lignoselulosa dan pada penelitian ini menggunakan batang tanaman jagung yang dapat dikonversi menjadi etanol. Produksi bioetanol yang menggunakan bahan baku tanaman yang mengandung pati atau karbohidrat, dilakukan melalui proses biokonversi karbohidrat menjadi gula (glukosa) yang larut dalam air. Glukosa dapat dibuat dari patipatian dengan menghidrolisis untuk memecahnya menjadi molekul glukosa dengan menggunakan asam, kemudian dilakukan proses peragian atau fermentasi gula menjadi etanol dengan menambahkan ragi Saccharomyces cereviceae sebagai biang fermentasinya.

Pengaruh pemberian variasi konsentrasi Saccharomyces cereviceae merupakan salah satu faktor untuk menentukan kadar bioetanol yang dihasilkan. Selain itu, lama fermentasi juga ikut berperan dalam menentukan jumlah kadar dan volume bioetanol selama proses fermentasi. Adapun data pengaruh konsentrasi Saccharomyces cereviceae terhadap produksi $(\mathrm{ml})$ dan kadar bioetanol (\%) limbah batang jagung dapat dilihat pada Tabel 1 dan 2 dibawah ini: 
Tabel 1. Produksi Bioetanol (ml) Berdasarkan Perlakuan Konsentrasi Ragi (S. cereviceae)

\begin{tabular}{|c|c|c|c|c|}
\hline \multirow{2}{*}{ Konsentrasi ragi (\%) } & \multicolumn{3}{|c|}{ Volume } & \multirow{2}{*}{ Rataan } \\
\cline { 2 - 4 } & Ulangan I & Ulangan II & Ulangan III & \\
\hline 1 & $90 \mathrm{ml}$ & $95 \mathrm{ml}$ & $93 \mathrm{ml}$ & 92,666 \\
\hline 2 & $97 \mathrm{ml}$ & $99 \mathrm{ml}$ & $87 \mathrm{ml}$ & 94,333 \\
\hline 3 & $92 \mathrm{ml}$ & $95 \mathrm{ml}$ & $98 \mathrm{ml}$ & 95 \\
\hline 4 & $99 \mathrm{ml}$ & $96 \mathrm{ml}$ & $97 \mathrm{ml}$ & 97,333 \\
\hline
\end{tabular}

(Sumber : Data Primer, 2018)

Berdasarkan Tabel 1 tersebut, terlihat bahwa produksi bioetanol berbahan dasar batang jagung dengan perlakuan konsentrasi $S$. cereviceae berbeda. Rerata volume bioetanol terendah ditemukan pada konsentrasi $S$. cereviceae $1 \%$ dengan nilai rataan sebesar 92,666 ml. Sedangkan, volume tertinggi ditemukan pada konsentrasi $S$. cereviceae 4\% dengan nilai rataan sebesar 97,333 ml.

Berdasarkan tabel diatas tersebut, menunjukkan bahwa konsentrasi $S$. cereviceae memberikan hasil yang berbeda terhadap produksi bioetanol. Produksi bioetanol terendah sampai tertinggi berturut-turut sebagai berikut; Konsentrasi ragi 1\%, 2\%, 3\% dan $4 \%$. Perbedaan volume bioetanol dari tiap perlakuan disebabkan karena semakin tinggi kadar $S$. cereviceae yang diberikan maka akan mempengaruhi interaksi $S$. cereviceae dalam menggunakan sumber nutrisi, dan semakin lama berinteraksi maka mortalitas dari sel ragi akan semakin turun dan akan berdampak terhadap optimalisasi proses fermentasi. Selain mengukur volume bioetanol, dalam penelitian ini juga dilakukan pengukuran kadar bioetanol dengan menggunakan piknometer dengan data seperti yang tertera pada Tabel 2 berikut:

Tabel 2. Kadar Bioetanol (\%) Berdasarkan Perlakuan Konsentrasi Ragi (Saccharomyces cereviceae)

\begin{tabular}{|c|c|c|c|c|c|}
\hline \multirow{2}{*}{ Konsentrasi ragi (\%) } & \multicolumn{5}{|c|}{ Kadar Alkohol } \\
\cline { 2 - 4 } & \multicolumn{3}{|c|}{ Ulangan } & \multirow{2}{*}{ Jumlah } & \multirow{2}{*}{ Rata-rata } \\
\cline { 2 - 5 } & I & II & III & & 0.26 \\
\hline 1 & 0.53 & 0 & 0.26 & 0.79 & 0.82 \\
\hline 2 & 0 & 1.72 & 0.73 & 2.45 & 0.93 \\
\hline 3 & 0.53 & 1 & 1.27 & 2.8 & 1.25 \\
\hline 4 & 0.73 & 1 & 2.02 & 3.75 & \\
\hline
\end{tabular}

(Sumber : Data Primer, 2018)

Berdasarkan Tabel 1 tersebut, bahwa kadar bioetanol berbahan dasar batang jagung dengan perlakuan kadar $S$. cereviceae memberikan hasil yang berbeda. Rerata kadar bioetanol terendah ditemukan pada perlakuan konsentrasi ragi $1 \%$ yaitu $0,26 \%$ dan rerata kadar bioetanol tertinggi terdapat pada perlakuan dengan konsentrasi ragi $4 \%$ yaitu $1,25 \%$. Adapun data perbedaan kadar bioetanol pada penelitian ini dapat juga dilihat pada Gambar 1 berikut: 


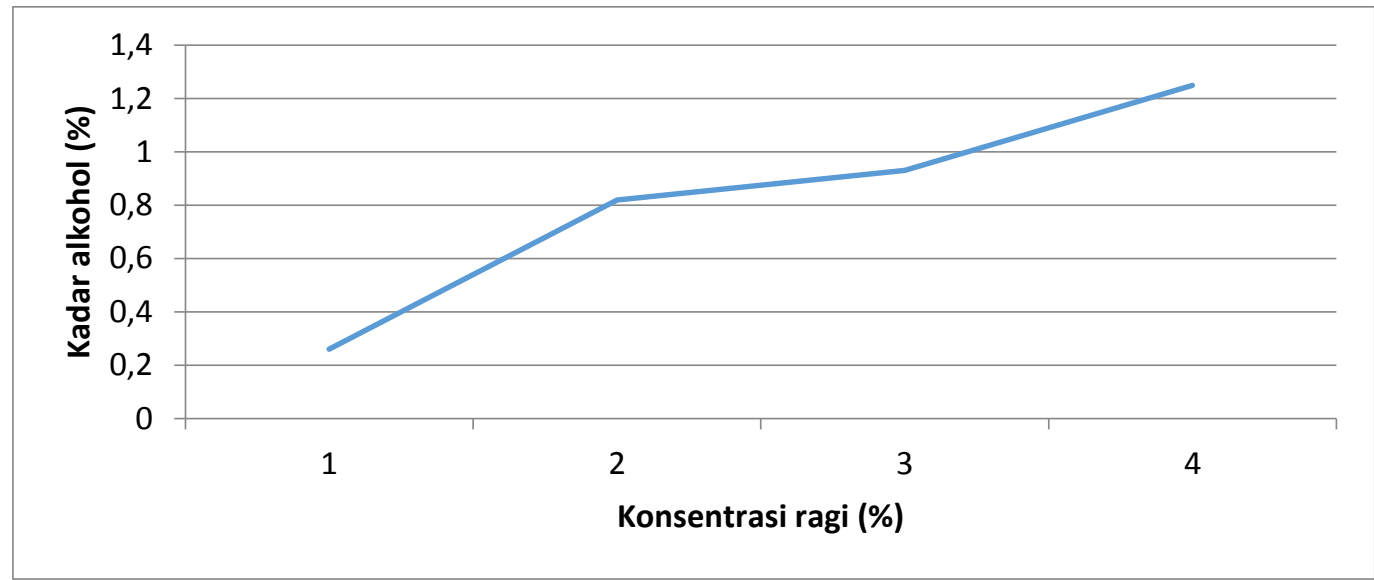

Gambar 1. Konsentrasi S. cereviceae dengan Rerata Kadar Bioetanol (\%)

Berdasarkan Gambar 1 tersebut, terlihat bahwa konsentrasi ragi (S. cereviceae) memberikan hasil yang berbeda terhadap kadar bioetanol. Kadar bioetanol tertinggi pada masing-masing perlakuan diperoleh pada perlakuan dengan konsentrasi ragi 3\% dan 4\% dengan lama fermentasi selama 168 jam (6 hari). Sedangkan, kadar bioetanol terendah diperoleh pada perlakuan dengan konsentrasi ragi $1 \%$ dan $2 \%$ dengan waktu fermentasi selama 144 jam (6 hari). Untuk melihat perbandingan rerata volume dan kadar bioetanol pada masing-masing perlakuan dapat dilihat pada Tabel 3 berikut:

Tabel 3. Perbandingan Rerata Volume (ml) dan Kadar Bioetanol (\%) terhadap Konsentrasi S. cereviceae

\begin{tabular}{|c|c|c|}
\hline Konsentrasi Ragi (\%) & Rerata Volume (ml) & Rerata Kadar (\%) \\
\hline 1 & 92,666 & 0,26 \\
\hline 2 & 94,333 & 0,82 \\
\hline 3 & 95 & 0,93 \\
\hline 4 & 97,333 & 1,25 \\
\hline
\end{tabular}

(Sumber: Data Primer, 2018)

Berdasarkan Tabel 3 tersebut, terlihat bahwa volume dan kadar bioetanol berbahan dasar batang jagung dengan perlakuan kadar $S$. cereviceae berbeda. Berdasarkan tabel tersebut, terlihat bahwa perlakuan yang paling baik untuk volume bioetanol berbahan dasar batang jagung adalah pada konsentrasi 4\%. Sedangkan, untuk kadar bioetanol konsentrasi yang paling baik adalah konsentrasi $4 \%$.

Tabel 4. Data Anova Pada Kadar Bioetanol

\begin{tabular}{|l|r|r|r|r|r|}
\hline & Sum of Squares & df & Mean Square & F & \multicolumn{1}{c|}{ Sig. } \\
\hline Between Groups & 1.523 & 3 & .508 & 1.431 & .304 \\
Within Groups & 2.837 & 8 & .355 & & \\
Total & 4.360 & 11 & & & \\
\hline
\end{tabular}

Berdasarkan output tersebut diketahui nilai signifikansi untuk pengaruh variasi konsentrasi Saccharomyces cereviceae terhadap kadar bioetanol adalah sebesar 0,304 lebih besar dari 0,05 sehingga dapat disimpulkan bahwa tidak terdapat pengaruh saccharomyces cereviceae yang signifikan terhadap kadar bioethanol. Menurut Asngad, dkk menyatakan bahwa semakin lama proses fermentasi dan banyak dosis ragi yang 
diberikan maka volume bioetanol semakin meningkat. Volume bioetanol tertinggi diperoleh pada 6 hari. Hal ini menunjukkan bahwa pada waktu tersebut aktivitas Saccharomyces cereviceae bekerja secara optimal serta kegiatan enzimatis tidak terhambat (Nasrun, 2015).

Waktu fermentasi berpengaruh terhadap perolehan bioetanol dimana semakin lama waktu fermentasi maka perolehan bioetanol akan meningkat. Namun, bila fermentasi terlalu lama maka nutrisi dalam substrat akan habis dan ragi Saccharomyces cereviceae tidak lagi dapat menfermentasi bahan. Pada konsentrasi ragi 3\% selama 6 hari diperoleh volume bioetanol sebanyak $95 \mathrm{ml}$, sedikit lebih rendah bila dibandingkan dengan konsentrasi ragi 4\% dimana diperoleh kadar bioetanol 0,93\%. Hal ini dikarenakan jumlah nutrisi yang tersedia tidak sebanding dengan jumlah Saccharomyces cereviceae yang lebih banyak, sehingga Saccharomyces cereviceae kekurangan makanan yang mengakibatkan kinerja Saccharomyces cereviceae menurun dan mengakibatkan volume bioetanol yang dihasilkan akan menurun juga.

Hasil penelitian diperoleh data pengaruh konsentrasi ragi (Saccharomyces cereviceae) terhadap kadar dan volume bioetanol batang jagung. Hal ini dapat dilihat pada Tabel 1 dan 2 diatas, yaitu kadar dan volume bioetanol berbahan dasar batang jagung berdasarkan konsentrasi ragi berbeda. Rata-rata kadar bioetanol tertinggi dihasilkan dari interaksi konsentrasi ragi 4\% dan waktu fermentasi 144 jam (6 hari) dengan rata-rata kadar bioetanol sebesar 1,25\%. Hal ini dapat dilihat perlakuan tersebut memiliki notasi berbeda. Sedangkan, rata-rata kadar bioetanol terendah dihasilkan dari perlakuan konsentrasi ragi $1 \%$ dan waktu fermentasi 144 jam (6 hari) dengan rata-rata kadar bioetanol sebesar $0,26 \%$. Hal ini menunjukan bahwa semakin besar konsentrasi ragi yang diberikan, maka semakin tinggi kadar bioetanol batang jagung yang dihasilkan, hal ini di duga karena pada konsentrasi ragi 4\% dengan waktu fermentasi 144 jam persediaan nutrisi dalam substrat masih tersedia sehingga memungkinkan aktivitas dari S. cereviceae bekerja secara optimal.

Berbeda dengan perlakuan konsentrasi ragi 1\%, 2\% dan 3\% aktivitas dari $S$. cereviceae tidak bekerja secara optimal, sehingga menghasilkan kadar bioetanol batang jagung menurun. Hal ini disebabkan kurangnya konsentrasi ragi yang diberikan sementara waktu fermentasi yang di gunakan selama 6 hari menyebabkan ketersediaan nutrisi dalam substrat menurun atau habis menyebabkan mikroba dalam suatu media telah mencapai fase kematian. Konsentrasi ragi merupakan satu faktor dari beberapa faktor yang mempengaruhi fermentasi etanol. Hal ini dikarenakan jika konsentrasi ragi yang diberikan terlalu sedikit akan menurunkan kecepatan fermentasi karena sedikitnya massa yang akan menguraikan glukosa menjadi etanol (Moeksin, 2010). Penurunan rata-rata kadar etanol pada batang jagung terjadi karena mikroba dalam suatu media telah mencapai fase kematian. Sholikha menyatakan bahwa fase kematian mikroba penghasil etanol ditandai dengan adanya penurunan produksi etanol. Selain itu, jika terlalu lama 
maka etanol yang sudah dihasilkan akan diubah oleh bakteri menjadi asam asetat (Sholikhah, 2010).

Hasil penelitian menunjukan bahwa kadar etanol tertinggi didapatkan pada perlakuan konsentrasi ragi yang terbanyak sebesar $4 \%$ dengan waktu fermentasi selama 6 hari. Hasil tersebut membuat peneliti mengasumsikan terdapat kemungkinan kadar etanol bisa mencapai kadar tertinggi jika konsentrasi ragi diperbanyak (lebih dari 4\%) dan atau waktu fermentasi dipercepat (kurang lebih dari 6 hari). Hal ini dikarenakan pada Gambar grafik 4.1 diatas menunjukan bahwa pada perlakuan tersebut kadar bioetanol dalam tujuh hari fermentasi telah mencapai puncak, sementara konsentrasi ragi (kurang dari 4\%) memiliki penurunan kadar bioetanol yang dihasilkan.

Hasil penelitian yang dilakukan oleh Muzid Syauqil Umam pengaruh konsentrasi ragi (Saccharomyces cereviceae) terhadap kadar bioetanol nira siwalan, sejalan dengan yang ditemukan oleh peneliti di lapangan kaitannya dengan hal yang mempengaruhi produksi dan kadar bioetanol yaitu konsentrasi ragi yang digunakan. Penelitian Muzid Syauqil Umam bahwa ada beberapa hal lain yang mempengaruhi produksi etanol dalam proses fermentasi nira siwalan selain konsentrasi ragi dan waktu fermentasi. Salah satunya adalah nutrisi dalam substrat yang menunjang kehidupan mikroorganisme penghasil etanol. Nutrisi tersebut meliputi unsur karbon (C), Nitrogen (N), fosfor (P), mineral-mineral dan vitamin-vitamin. Oleh karena itu, perlu adanya penelitian lebih dengan menambahkan nutrisi dalam nira siwalan untuk mengetahui seberapa besar pengaruh nutrisi terhadap produksi etanol serta untuk mengetahui jumlah nutrisi yang tepat agar didapatkan kadar etanol tertinggi dalam proses fermentasi nira siwalan (Umam, 2018). Begitupun dengan hasil yang didapatkan oleh peneliti bahwa selain faktor bahan baku, konsentrasi ragi serta waktu fermentasi, ketersediaan nutrisi dalam substrat juga perlu ditingkatkan untuk menunjang kehidupan mikroorganisme sehingga dapat menghasilkan kadar etanol batang jagung yang lebih tinggi.

Fermentasi etanol juga disebut sebagai fermentasi alkohol, adalah proses biologi dimana gula seperti glukosa, fruktosa, dan sukrosa diubah menjadi energy dan juga menghasilkan etanol dan karbon dioksida sebagai produk sampingan. Karena proses ini tidak membutuhkan oksigen, melaingkan khamir yang melakukannya, maka fermentasi etanol digolongkan sebagai respirasi anaerob. Sebelum dilakukan fermentas, satu molekul glukosa dipecah menjadi 2 molekul piruvat. Proses ini dikenal dengan nama glikolisis. Glikolisis merupakan langkah pertama dari respirasi aerob yang bertujuan menghasilkan energi dalam bentuk NADH dan ATP dari molekul glukosa. Olehnya itu, untuk memecah glukosa menjadi alkohol dilakukan secara anaerob (tanpa $\mathrm{O}_{2}$ ) oleh aktivitas khamir Saccharomycs cereviceae. Adapun mekanisme proses fermentasi glukosa menjadi etanol dapat dilihat pada Gambar 2 di bawah ini: 


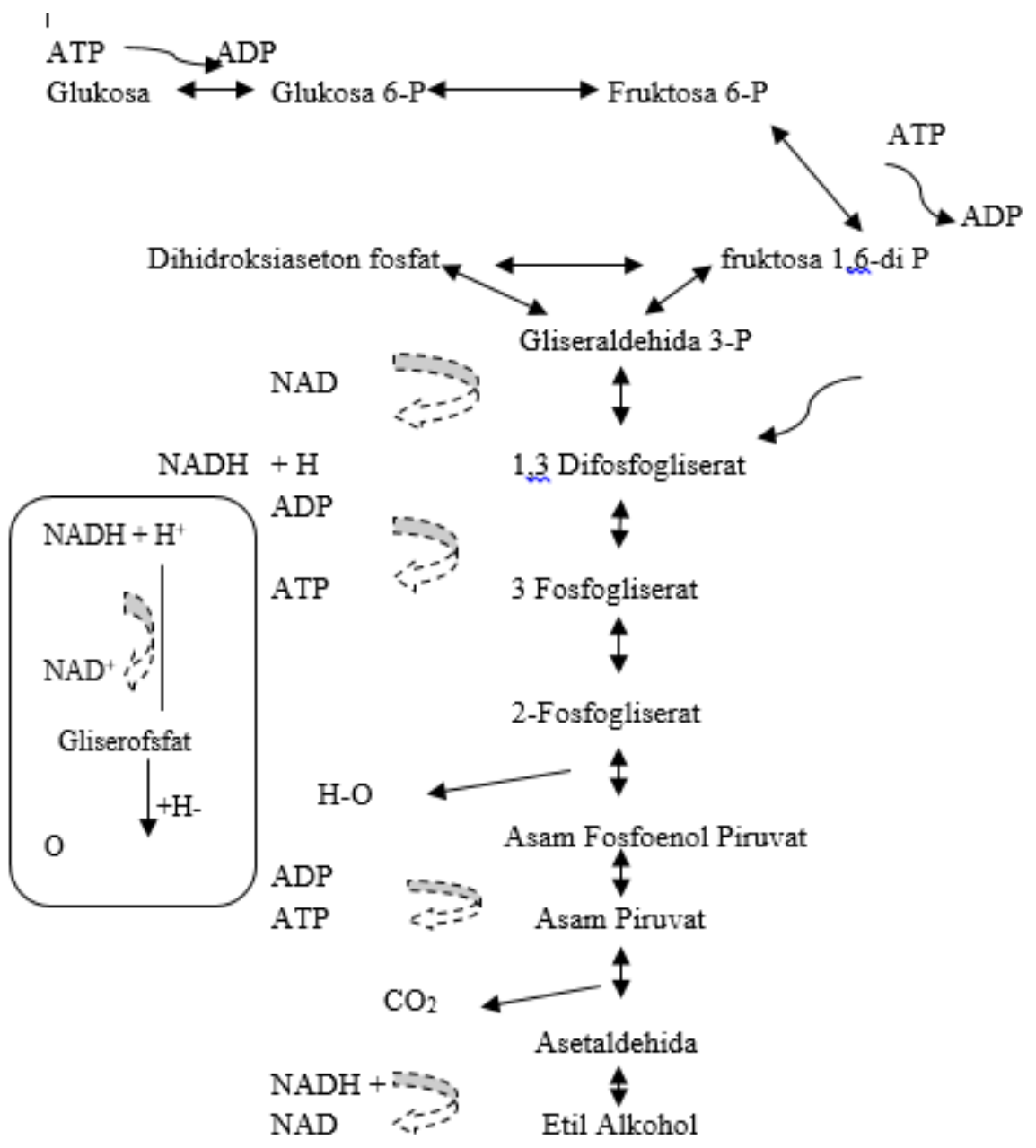

Gambar 2. Mekanisme Fermentasi Glukosa Menjadi Etanol

Berdasarkan Gambar 2 tersebut, bahwa mekanisme fermentasi glukosa menjadi etanol diawali dengan bahan glukosa yang kemudian dilisis di sitoplasma. Hasil pemecahan 2 piruvat, 2 NADH dan 2 ATP. Proses berpindah ke mitokondria jika ditempat itu banyak oksigen, namun karena Saccharomyces cereviceae ini tidak perlu oksigen dalam repsirasinya maka asam piruvat akan di ubah menjadi asetaldehid yang kemudian dijadikan etanol. Asam piruvat diubah menjadi asetaldehid sehingga dilepaskan molekul $\mathrm{CO}_{2}$ Asetaldehid segera mengikat ion $\mathrm{H}^{+}$dari penguraian NADH menjadi NAD maka sebagai akseptor ion $\mathrm{H}^{+}$dalam proses fermentasi etanol ini adalah asetaldehid. Pengikatan ion $\mathrm{H}^{+}$oleh asetaldehid akan membentuk senyawa etanol jadi produk fermentasi ini adalah 2 etanol, $2 \mathrm{CO}_{2}$ dan 2 ATP (Fachry, 2013).

\section{KESIMPULAN}

Kesimpulan dari penelitian ini: (1) Produksi bioetanol berbahan dasar limbah batang jagung dengan konsentrasi ragi Saccharomyces cereviceae berbeda. Rerata kadar BIOLOGI SEL (VOL 8 NO 1 EDISI JAN-JUN 2019 ISSN 2252-858X/E-ISSN 2541-1225) PAGE 68 
bioetanol terendah ditemukan pada konsentrasi ragi $1 \%$ yaitu $0,26 \%$ dan kadar tertinggi ditemukan pada konsentrasi ragi $4 \%$ yaitu sebesar 1,25\%. (2) Produksi bioetanol berbahan dasar limbah batang jagung dengan waktu fermentasi 6 hari dan konsentrasi ragi Saccharomyces cereviceae berbeda. Rerata volume bioetanol terendah ditemukan pada waktu fermentasi 6 hari dengan konsentrasi ragi 1\% yaitu sebesar 92,666 ml dan volume tertinggi ditemukan pada waktu fermentasi 6 hari dengan konsentrasi ragi $4 \%$ yaitu sebesar 97,333 ml.

\section{DAFTAR PUSTAKA}

Ahmad Rasyidi, dkk. (2013). Pembuatan Bioetanol Dari Limbah Tongkol Jagung Dengan Variasi Asam Klorida Dan Waktu Fermentasi. Jurnal Teknik Kimia No. 1, Vol. 19.

Ahyar Ahmad. (2014). Bioethanol Production From Cellulose In Red Algae Gracilaria Verrucosa By Separated Hydrolysis And Fermentation System Using Trichoderma viride And Zymomonas mobilis. International Journal of Pharma and Bio Sciences.

Abdulkarem Saka Member, dkk. (2015). Production and Characterization of Bioethanol from Sugarcane Bagasse as Alternative Energy Sources Proceedings of the World Congress on Engineering 2015 Vol II WCE 2015, July 1 - 3, 2015, London, U.K.

Felipe Scoot, Julianto Kintero dkk. (2013). Process design and sustainability in the production of bioethanol from lignocellulosic materials. Electronic Journal of Biotechnology ISSN: 0717-3458

Deky Seftian, dkk. (2012). Pembuatan Etanol Dari Kulit Pisang Menggunakan Metode Hidrolisi Enzimatik dan Fermentasi. Jurnal Teknik Kimia. No. 1, Vol. 18.

Elgina May Lestari, dkk. (2015). Pembuatan Bioetanol Dari Limbah Tongkol Jagung Menggunakan Proses Simultaneous Sacharificatian and Fermentation (SSF) Dengan Variasi Konsentrasi Enzim dan Waktu Fermentasi. JOM FTEKNIK No. 2, Vol. 2.

Fitriani, dkk. (2013). Produksi Bioetanol Tongkol Jagung (Zea mays) Dari Hasil Proses Delignifikasi. Jurnal Of Natural Science No. 3, Vol. 2.

Mir Naiman Ali dkk. (2011). Ethanol Fuel Production Through Microbial Extracellular Enzymatic Hydrolysis And Fermentation From Renewable Agrobased Cellulosic Wastes. International Journal of Pharma and Bio Sciences.

Mustafa Balat and Hava. (2009). Balat Recent trends in global production and utilization of bio-ethanol fuel Sila Science and Energy Unlimited Company, Mekan Sok, No 24, Trabzon, Turkey.

Muzid Syauqil Umam. (2018). Pengaruh Konsentrasi Ragi Roti (Saccharomyces cerevicea) dan Waktu Fermentasi Terhadap Kadar Bioetanol Nira Siwalan (Borassus flabeliffer L.). Jurusan Biologi UIN Maulana Malik Ibrahim Malang. 
Nasrun. (2015). Pengaruh Jumlah Ragi dan Waktu Fermentasi Terhadap Kadar Bioetanol yang Dihasilkan Dari Fermentasi Kulit Pepaya. Jurnal Teknologi Kimia Unimal. No.2, Vol.4.

Putra Asga Elevri dan Surya Rosa Putra. (2006). Produksi Etanol Menggunakan Saccharomyces cerevicea Yang Dimobilisasi Dengan Agar Batang. Akta Kimindo No. 2, Vol. 1.

Rosdiana Moeksin, dkk. (201)5. Pembuatan Bioetanol Dari Kulit Pisang Raja (Musa sapientum) Menggunakan Metode Hidrolisis Asam dan Fermentasi. Jurnal Teknik Kimia No. 2, Vol. 21.

Sholikhah. (2010). Kajian Kadar Etanol Air Nira Siwalan dan Asam Asetat Dalam Cairan Niran Siwalan (Borassus flebeliffer L.) Menggunakan Metode Kromatografi Gas $(G C)$. Skripsi. Jurusan Kimia UIN Maliki Malang.

Sri Kusumastuti Hayuningtyas, dkk. (2014). Produksi Bioetanol Dari Jerami Padi (Oryza sativa) Melalui Hidrolisis Asam dan Fermentasi Dengan Saccharomyces cereviceae. Jurnal Bioteknologi No. 1, Vol. 11.

Siti Fatimah, dkk. (201)4. Penentuan Kinetika Hidrolisis Enzimatis Dalam Pembuatan Bioetanol Dari Tandan Kelapa Sawit. JKK No. 3, Vol. 4

Uum Umiyasih dan Elizabeth Wina. (2008). Pengolahan dan Nilai Nutrisi Limbah Tanaman Jagung Sebagai Pakan Ternak Ruminansia. Wartazoa No. 3, Vol. 18.

Zul Fadly Khaira, dkk. (2015). Pembuatan Bioetanol Dari Limbah Tongkol Jagung Menggunakan Proses Simultaneous Sacharificatian and Fermentation Dengan Variasi Konsentrasi Enzim dan Waktu Fermentasi. JOM FTEKNIK No. 2, Vol. 2. 